\title{
CONSELHOS DE HYGIENE SEXUAL E MORAL
}

(Conclusão)

\section{PROPHYLAXIA DOS MALES VENEREOS}

Pela leitura do que dissemos, uma preoccupação maxima deve ter tomado o espirito dos leitores, qual a de realisar a prophylaxia dessas molestias, isto é, combatel-as, afim de se poupar e poupar tambem sua familia a tão grandes riscos.

Mas eomo realisar tal prophylaxia?

Eis o problema. A prophylaxia dos males venereos tem sido tentada de varios modos e o tempo já ise encarregou de mostrar o valôr de cada um delles. Um que parecia satisfactorio era a regulamentação da prostituição, e que consiste em registar todas as mulheres que se entregam ao meritricio e submettel-as, de tempo em tempo, a um exame medico que verificaria o seu estado de saude. Esse processo fracassou por causa da grande maioria de mulheres que escapavam á regulamentação. Emfim, ficou mośtrado que a prophylaxia dos males, venereos tem de correr por conta propria do individuo, que teria de medir todos os seus actos nos assumptos que se referem á vida sexual. Ora, mil e um modos de evitar o contagio têm sido expostos, os quaes sulbmettem 0 corpo do individuo a uma série de actos e de manobras verdadeiramente indignos e todos falham sendo cada um delles posto de lado para ser substituido por outro mais em moda.

Só um processo tem provado 'infallivel, só uma regra de conducta mostrou-śe intransponivel aos males venereos: é a continencia sexual, a abstinencia completa do acto sexual até o matrimonio. A grita que contra ella se levanta é enorme e parece o 'clamor de uma catastrophe.

- E' impossivel! E' um attentado contra a natureza, é uma violencia feita contra a propria saúde...

Quanto á violencia contra a saúde, cremos já ter respondido cabalmente quando tratámó das accusações lançadas contra a abstinencia. Vamos, agora, apenas, tratar da impossibilidade que lihe emprestam. Essa impossibilidade é plenamente justificavel se se tomar em conta o estado, de espirito, a educação víciosá que nossa mocidade recebe, para não dizer a falta de educação, que é nosso maior mal. Entretanto, se o rapaz souber governar seu 
espirito, dando-lhe o alimento sadio da bôa convivencia e da bôa leitura, a declamada "necessidade sexual" passará a ser o simples "desejo sexual" que a Natureza creou. A grande difficuldade está na consecussão deste objectivo, dada a hostilidade do meio em que se vive e a falta de quem dirija o rapaz, intento que se attribue a este folheto. A continencia sexual é possivel; diremos, mesmo, é facil, desde que o rapaz o queira (e nem pode deixar de querer, conhecendo-lhe os beneficios) e saiba educar o seu espirito. Do conjunto de providencias a se tomarem para a prophylaxia dos males venereos pela continencia sexual a mais importante é a referente a leitura. o que nós lemos constitue o maior guia de nosso pensamento, que de nenhum modo pode se esquivar á inrluencia daquillo que está continuamente sob os olhos e no pensamento. A bôa leitura, mas a bôa leitura com exclusão da outrạ, a má, é uma garantia e um paśso dado para a pureza do espirito e consequente pureza do corpo. Os bons livros nạ̃o faltam; qualquer rapaz encontrará com seus professores, conselhos e indicações para a compra de livros que desenvolvem a imaginação sem despertar os maus pensamentos adormecidos no fundo de nosso ser. A causa principal do grande numero de abstemios sexuaes das raças anglo-saxonias está em que a literatura de.las é perfelta. mente limpa e ao se tomar nas mãos um de seus livros tem-se a certeza de que se vae ler cousa seria e honesta. O contrario succede com a grande maioria dos livros francezes, onde a cada pagina que se volta corre-se o risco de receber no rosto o halito fetido das mais descabelladals scenas de impudor e immoralidade. 0 rapaz que ler os bons livros terá grandemente facilitada sua marcha para o Iddal de pureza que architectou.

Outro passo a dar na prophylaxia do espirito para a prophylaxia do corpo é o das relações e amizades que se mantêm. Os amigos, mais frequentemente que os livros, influem no espirito do 'rapaz, e além disso, o fazem com o maior poder da expressão, da minucia e, sobretudo, do exemplo, que, quanto peior, mais timbra em se exhibir e querer se impôr. Os bons amigos ajudam a vencer os obstaculos e, se se encontra um que tenha accendido no coração a mesma chamma de pureza, então marcha-se impavido em direcção á Luz que brilha longinqua, meio apagada pela cerração espessa dos preconceitos e dos tropeços da rotina. Um amigo mais edoso, já maduro e experimentado, será para qualquer rapaz um auxilio importantisãimo na educação de seu caracter. E não quero terminar estas palavras a respeito dos amigos sem transcrever aqui um pequeno trecho da obra "Juventude", de Charles Wagner, cujos livros são verdadeiras perolas e cuja leitura aconselhamos a quantos queiram aperfeiçoar-se e melhorar: "A amizade nos 
fortalece nessas lutas asperas e terriveis que a juventude chamada a sustentar pelas causas que mais lhe falam á alma e que muitas vezes não são bem viśtas pelo mundo". Não parece terem estas palavras sido escriptas exprezsamente para o valôr da amlzade na conquista da pureza?

Os divertimentos com que um rapaz conta hoje para o eimprego de suas horas de lazer são tambem obstaculos serios á consecução do Ideal de pureza que the propomos. A liberdade de costumes e de expressões invadiu por tal forma as diversas eápecies de divertimentos, do theatro ao cinema, das dansas ás confeitarias. que frequentar com assiduidade qualquer deases logares é se expor a grandes riscos. Saber se conter, tal é a divisa a se obedecer. Um descuido, e era uma vez uma bôa intenção. E não é somenté por suas deleterias influencias sobre, o espirito e o moral do rapaz, senão tambem por seu caracter anti-hygienico que certos divertimentos devem ser condemnados. Os salóes de dansa e de espectaculos theatraes ou cinematographicos, pela viciação do ar, pela poeira, pelo calôr, são altamente prejudiciaes á saúde physica do individuo. As dansas de hoje, principalmente as doa bailes publicos, a tanto por cabeça, se afastam tanto das regras de cortezia e recato de ha annos que sua pratica frequente é nociva ao rapaz que deu o sèu espirito uma certa rota elevada a ser seguida.

Em summa, é preciso que o rapaz faça a hygiene do espirito com o maxima rigor. Esses recursos que acima ficam indicados são apenas um subsidio para que o rapaz alce as azas do espirito $\in m$ vôo mais largo, formando e aicariciando um Ideal que occupe - espirito e o torne incompativel com praticas menos elevadas. Esse Ideal pode ser ou uma grande affeição - e quantos não são os rapazeส̃ que por amizade a uma moça não se mantêm púros? - ou uma grande dedicação, e aqui a Caridade offerece largo campo a quem queira se preoccupar, apenas, com os grandes problemas sociaes do alcoolismo, da indigencia, da mendicidade e outros, problemas esses que nunca se é demasiado moço para pensar nelles.

A adaptação da realidade aos sonhos que se fazem é muito séria. Qual o rapaz que não tem um cantinho do seu coração uma visão que elle mesmo não sabe objectivar bem, na qual reluza um par de olhos e um sorriso de moça, que elle mesmo não sabe quem é, a illuminar uma casinhola que será um lar de ternura e affeicões? Comprehende-se que, em taes circumstancias, o individuo pense na possibilidade de para lá levar a syphilis, a gonorrhéa e semelhantes? Que anniquille, por uma hora de um prazer duvidoso, o encanto desse lar, a saúde da esposa e dos filhos? Creio que nenhum rapaz que pense um pouco seriamente na constituição 
de sua futura familia se submetta á possibilidade de ver tão torpemente desmanchado um sonho tão lindo e encantador. 0 rapaz que realmente queira conseguir o estado de pureza de corpo que lhe assegure a realisação integral de seus ideaes precisa seriamente tratar de purificar seu espirito, não dando guarida aos máos pensamentos que porventura queiram assaltal-o, sendo inflexivel para comsigo mesmo, e não permittir a mais leve preoccupação com assumptos indecorosos e immoraes. Os rapazez religiosos enicontrarão nos sacramentos e nas orações recurso que raramente falha.

Com um pouco de energia de vontade vence o rapaz bem intencionado as primeiras tentações, as mais fortes, e acostuma-se á limpeza hygienica do espirito, em geral tão lamentavelmente descuradas.

Mas, para que tão nobre intuito seja alcançado, mistér se faz dar ao espirito base solida sobre que se assente, isto é, cuidar do corpo como uma joia preciosa para a qual todas as attenções sejam poucas. Não se pense, porém, que aqui attenção quer dizer excesळo de cuidado 'e, por consequencia, enfraquecimento.

Cuidar no corpo é enriquecel-o na prática da vida regrada e methodica, conservando-o nutrido, limpo e fortalecido. Falando assim já 'dissémos quasi tudo. A nutrição se 'taz pelo que o individuo come, bebe e dorme, pois o somno nada mai é que um reparador para as forças gastas e esgotadas. Bem comer, bem beber e bem dormir, eis a trindade hygienica que cumpre praticar.

O bem comer, comprehende-se, não té comer muito nem comer iguarias custosas e complicadas; é comer sufficientemente na quantidade, moderadamente nod condimentos e satisfactoriamente na digestibilidade do que se come. Os alimentos devem ser sufficientes para alimentar, temperados com moderação e que sejain de digestão facil. Os excessos gastronomicos são uma porta larga e franca aberta ás affecções do estomago e portanto debilitiamento geral e consequente entrada de diverșas molestias que estão apenas á espera de que a resistencia do organismo se embote. Bem beber, igualmente, significa o afastamento dos excessos do "copo, aos quaes ninguem negará importancia na producção de diversas molestias e graves. Não diremos "beba sóinente agua". Embora esșa seja a nossa regra, sabemos que ha sempre nos rapazes uma vaidadezinha que os impede de renunciar de vez ás bebidas alcoolicas. O receio de ser chamado "fracalhão" pode muito na conducta de um rapaz. Bem dormir, já se sabe, não se refere exclusivamente na duração do somno, que deverá ser o mais prolongado possivel; refere-se tambem ao modo por que se dorme. Quarto arejado - e quem se acostumou a dormir em quarto com venezianas ou com folhas de vidro entreabertas não supporta os quartos 
abafados - cobertas apenas sufficientes, deitar sempre que possivel de lado e nunca de costas, só se deitar com somno e levantar ao despertar, evitando, assim, as demoras no leito estando acordado, dormir com a icabeça sempre um pouco mais elevada que o corpo, dormir em cama que não seja excessivamente fofa, por prejudicial, nem demasiadamente dura, por incommoda, dormir com roupas folgadas, que não perturbem a respiração, são algumá̃ regras a observar e cujo costume tem o mais alto valôr para a pessoa que as pratica.

Bem nutrido o corpo, é preciso que seja bem limpo, e a frequencia das relações de uma pessôa com a agua e o sabão dão bem uma medida da hygiene do espirito dessa propria pessôa; um individuo sujo por fora não pode ser limpo por dentro. A limpeza, do mesmo modo que a educação, é um habito que cumpre adquirir e conservar. O corpo limpo é uma sentinella sempre attenta ao perigo; o corpo sujo é como a praça de guerra sem trincheiras, nem muralhas, sem armas nem soldados.

Resta, ainda, o fortalecimento do corpo e este conseguir-se-á com o uso, não abuso, do exercicio physico, beneficio precioso que a Natureza concedeu ao homem são. O exercicio physico, facilitando a circulação do sangue, favorece a eliminação dos productos prejudiciaes ao organismo. Além disso, pelo maior trabalho dado aos diversos orgãos, activa-lhes o funccionamento, aperfeiçoando os resuitados. E não é só, o exercicio physico traz ao individuo que o pratica a consciencia de seu proprio valôr, a noção de que ś forte e, portanto, o desejo de conservar essa força contra os males que o possam aviltar. Mas não se deve ter̀ a ambição de grandes musculos, sem se preoccupar em que o funccionamento dos orgãos não seja perfeito; isso é bom para athleta de circo de cavallinhos. O que se quer é a saúde, que se obtem com o exercicio moderado. A gymnastica suéca presta-se optimamente a esse fim. Poder-se-́́ dizer que 06 individuos que mais se gabam dos prazeres sexuaes são justamente aquelles individuos que se dão como esportistaz de valôr. Mas taes individuos são duplamente reprovaveis. Primeiro, porque têm exclusivamente a mania do "muque" pois, ao mesmo tempo que se gabam de força, contráem molestias que lhes vão minar as fontes da vida. Segundo, porque lhes falta comp'ptamente a educação do espirito, sobre que tanto insistimos e da qual talvez nunca tenham ouvido falar e nem suspeitem a existencia.

Com taes praticas creará o rapaz para o seu corpo um estado de saúde e forşa que influirá beneficamente sobre seu espirito, dando-lhe uma repugnancia instinctiva por esses lu'panares, que enfermam o corpo e a alma, a saúde e a conducta. 
Tendo dado a conhecer alguns dos principaes preceitos de hygiene do espirito e do corpo com que a prophylaxia dos males venereos se torna facil, queremos applical-as a um outro mal, frequente e prejudicialissimo, a masturbação ou onanismo, que é a excitação artificial dos orgãos genitaes. Esse vicio é uma das imputações que fazem a continencia sexual, dizendo que esta o provoca. Aqui diremon o que vimos affirmar desde o principio, que $o$ individuo de mente limpa nadda tem a receiar. $E$ aquelles que porventura são delle victimas devem, num esforço que será nrodigamente recompensado, fugir á sua pratica para não comprometterem sua moral, e pouparem a sua saúde. A masturbação é um despenhadeiro em que a victima cada vez mais escorrega, para encontrar, lá no fundo, os mais cruciantes soffrimentos moraes e materiaes. O infeliz perde sua vivacidade e alegria, esquiva-se aos companheiros e ás pessôas de sua familia, cae num estado de indifferença por tudo o que o cerca, não é capaz de trabalhar nem de estudar, deprime-se moralmente, foge ao olhar inquiridor de seus paes, ou não dorme ou tem o somno agitado, não se alimenta nem se diverte, excita-se com o ruido e com a agitação e vae por esse caminho até as mais grave s periurbações do systema nervose, perturbações que exigirão um tratamento demorado e intenso, que nem sempre consegue triumphar sobre o mal. Tudo consequencia da fa'ta de energia, da fraqueza criminosa de vontade que não soube reprimir um desejo vicioso e impuro! A hygiene do corpo e do espirito tal como a aconselhamos, dá ás victimas do onanismu as armas para a lucta, da qual, se quizer, sahirão vencedoras.

\section{RESPONSABILIDADE DO INDIVIDUO INFECCIONADO COMO PROCEDER UMA VEZ QUE SE INFECCIONA}

Os leitores devem estar de posse de sufficientes conhecimentos e recursos para evitar os males venereos: conhecimentos de suas consequencias e recursos para a sua prophylaxia. Como dissémos, a unica prophylaxia dos males venereos é a continencia sexual prematrimonial. Esta é a prophylaxia ordenada pela sciencia \& pela moral. Entretanto, ha uma outra prophylaxia não tão efficiente mas nem por isso desprezivel, e que é a que se deve adoptar no caño de, por um descuido da razão e da vontade, apanhar-se uma infecção venerea. Esta prophyłaxia é tendente a impedir maiores estragos na saúde do individuo, mas principalmente para evitar a propagação do mal pelas pessôas que se ponham em contacto 
com o individuo infeccionado. Em taes casos sómente um medico poderá ditar ao rapaz um programma de hygiene e therapeutica efricienie e seguro. Quando falamos dos perigos dos males veno. reos, frisando os seus meios de contagio, fizémos ver que tanto o blenorrhagico como o syphilitico e tambem o portador do bacillo de Ducrey podem, por variados meios, pôr o microbio infectante em contacto com pessôas sans, acarretando-lhes a molestia. O puz blenorrhagico, o producto humido dos cancros molle e duro, a saliva do individuo que tem placas mucosas, tudo é meio de contagio. Assim sendo, se o individuo não se submette a um regimem de asseio para evitar que taes productos se espa:hem e a acçã ? de medicamentos para que taes productos não mais sejam produzidos, elle póde tornar-se restponsavel pela causa da molestia em pessôa sadia, quem sabe de seus proprios paes e irmãos. 0 individiuo que tem syphilis terciaria padece mas não transmitte o mal; emquanto que o que tem o cancro duro está a distribuir microbios de syphilis a todos os que se lhe approximam. Portanto, infeccionado, cabe ao individuo correr ao medico, sem tardança nem demoras. E convém aqui chamar a attenção dos leitores para os charlatães que em annuncios vistosos engodam a bôa fé dos incautos, promettendo-lhes uma cura absurda pela rapidez. Deve-se fugir de taes individuos, cujo fim é o dinheiro do rapaz aterrorisado pelas ameaças que o proprio charlatão lhe faz. 0 medico consciencioso e de confiança é o melhor recurso para o rapaz infeccionado, que não deverá sentir-se acanhado em the pedir conselhos, pois estes irão evitar que os membros de sua familia se infeccionem com molestias tâo temiveis.

Esperamos, entretanto, que tal eventualidade não se apresente uma vez sequer na vida dos rapazes que nos leram. O receio á molestia, mas tambem, e principalmente, o amôr á sua futura prole e o respeito ao que manda a Moral que não obedece a circumstanças, farão com que ao rapaz se mostre o amor mercenario como o mais influerte productor de maleficios, desgraças e remorsos.

\section{ANNUNCIEM NA "REVISTA DE MEDICINA"}

Mediante pedido enviamos tabellas de preços e prestamos promptamente quaesquer outras informações. 